\title{
Medical Schools Ignore the Nature of Consciousness at Great Cost
}

\author{
Anoop Kumar, MD, MMgt ${ }^{*}$ \\ DOI: 10.18297/jwellness/vol3/iss2/3 \\ Website: https://ir.library.louisville.edu/jwellness/ \\ Affiliations: ${ }^{1}$ https://www.secondmindmedicine.com/physiciangroup \\ Recommended Citation: Kumar, Anoop (2021) "Medical Schools Ignore the Nature of Consciousness at \\ Great Cost," Journal of Wellness: Vol. 3 : Iss. 2, Article 3.
}

Received Date: May 17, 2021

Accepted Date: June 5, 2021

Publication Date: July 9, 2021
Consciousness is not a popular topic for new exploration in my hospital. In my field of emergency medicine, we talk about consciousness only in the context of patients who "pass out," have altered mentation, or need sedation. We need to change this, because behind these casual considerations of consciousness is an unexamined, ubiquitous, powerful, and unspoken philosophical assumption: Matter, including neurons and the brain, is primary, and consciousness is its product.

At first glance, the assumption of the primacy of matter may seem obvious. Doesn't the brain create thoughts? Can't we see a functional MRI scan of the brain light up when a person is conscious and thinking? We know that thinking, electrical activity in the brain, and the lighting of pixels on a display are correlated and concurrent, but the conclusion that the brain is the cause of thinking comes at the expense of ignoring evidence, including:

- Beginning a practice of mindfulness meditation correlates with subsequent changes in brain structure, suggesting attention can organize matter [1].

- High-level intelligent thinking can happen despite the loss of a majority of the brain's volume and distortion of its tissue [2].

- Psychedelic use leads to rich, vivid experiences despite decreases in brain activity $[3,4,5]$.

- Many people who experienced cardiac arrest report rich, vivid experiences despite decreases in cerebral blood flow [6].

- Many children have specific, documented memories of another lifetime, the details of which are historically-verified in some cases [7]. Consciousness, in these cases, does not appear to be localized to the brain.

Beyond this evidence, uncritically assuming the primacy of matter also comes at the expense of ignoring gaps in our knowledge, including:
- We don't know what consciousness is. Over many years, the nature of consciousness has gone from being scientific taboo to becoming one of the biggest questions in science $[8,9]$.

- We don't know what matter is. Over many years, physicists have refined our understanding of matter from that of balls and sticks to fields of energy that extend throughout space to abstract information to even mind [10-14].

- We are not trained in introspective practice. While many dabble in and even diligently practice introspection, there is no formal, systematic approach to this in medical school curricula.

- We are not trained in the basics of philosophy of mind or in the main points of wisdom traditions with centuries of experience in exploring the relationship between the subjective and objective world. Medical students need not be philosophers per se, but a certain love of wisdom is essential to be a doctor-a word that is derived, after all, from the Latin root to teach.

Can we rationally make sense of the possibility that consciousness exists beyond the brain without contradicting the mountain of useful knowledge we have gained from neuroscience and the scientific method in general? We surely can by postulating at least two levels, or hierarchies, of consciousness, [15] just as we can consider $\mathrm{H} 2 \mathrm{O}$ at two levels of hierarchy: vapor and ice.

At the congealed, individuated, "ice"-level of organization, consciousness is personal, with discrete boundaries. Your consciousness is not my consciousness nor her consciousness. Because we experience it as subtle and less tangible than matter, such as a brick or a brain, this level of consciousness is sensorially-not rationally-separated from matter, leading to the philosophy of mind-body dualism that medical science subscribed to centuries ago. The subtlety of this consciousness also makes it difficult to investigate and relatively easy to ignore. For 
these reasons, individuated consciousness came to be believed as being secondary to the brain-not as a consequence of critical investigation but simply due to habitual intellectual neglect.

At the undifferentiated, non-discrete, "vapor"-level of organization, consciousness is trans-personal, trans-object, and non-local-a scientifically viable hypothesis [16] that is also consistent with the evidence presented above. Here, there is no divide between matter and mind because both are in their potential state, just as liquid water and solid ice exist in a potential state as vapor.

The relationship between the individuated and undifferentiated nature of consciousness is the relationship between the part and the whole. The intellectual position that we are essentially made of small parts is one-sided and cuts us off from a deeper dimension of identity that is critical to our sense of being in the world as clinicians, patients, and people in general.

Obstacles to pursing the above lines of inquiry include fear of stepping away from professional and social groupthink, personal misgivings about pursuing learning that may contradict religious beliefs, the time and diligence required to dig up relevant research and sort through facts and opinions, and unfamiliarity with and fear of introspective practice. These obstacles are great, no doubt, but there are many reasons why we will face them directly, including but not nearly limited to physician suicide, chronic disease, high healthcare costs, intellectual satisfaction, taking pride in our work, and eventually, public demand. At the root of re-visioning all these is one simple conclusion we must honor: We are human beings, not only human bodies.

Medical school lectures and workshops on stress reduction, mind-body practices, and integrative medicine have been a good start, but they mostly treat the question of the nature of consciousness as ancillary when in fact it is the elephant in the room. It's time to get to the heart of the matter, pun intended. It's time to formally add cross-disciplinary training and critical comparative thinking about consciousness across all four years of medical education. We must learn to not only deepen and broaden our experience, but also recognize it through the language of various disciplines and communicate a more complete framework for wellbeing with classmates, our patients, and the public at large.

The heart of such a curriculum is introspective practice, because all rationality and science can only build on our most basic pre-verbal appreciation of ourselves and the world. This means we must do what we can to increase our awareness of these pre-rational factors because they inevitably influence how we think about what we experience. I am not necessarily referring to accessing the subconscious mind in the sense it is usually talked about. I am instead referring to developing our awareness of the sense of identity, thinking, feeling, perceiving, and of space, time, relationship, and the "other." This is the beginning of an approach many spend an entire lifetime practicing, so there is no shortage of "material" to discover over four years of medical school and on into residency, fellowship, and the rest of our careers.

While developing this introspective practice as part of a curriculum in consciousness studies, medical students must also have the opportunity to learn from and question long-time introspective practitioners, integrative medicine faculty, and professors of philosophy, physics, neuroscience, computer science, art, music, and more subjects to inquire into the gray zone between mind and matter and learn how different mindsets approach, categorize, label, and communicate their findings.

The ultimate teacher, then, will be the medical students themselves, who will organize their experiences-intuitive, conceptual, emotional, perceptual, and more-into a cross-disciplinary framework consistent with science, philosophy, and direct, living experience. Undoubtedly, they will see themselves, each other, and their patients more completely and bring fresh eyes to our approaches to diagnosis, treatment, healing, and wellbeing. This is the great reward awaiting us. Our profession demands no less.

\section{REFERENCES}

1. Tang YY, Hölzel BK, Posner MI. The neuroscience of mindfulness meditation. Nat Rev Neurosci. 2015 Apr;16(4):213-25.

2. Lewin R. Is your brain really necessary? Science. 1980 Dec;210(4475):1232-4.

3. Muthukumaraswamy SD, Carhart-Harris RL, Moran RJ, Brookes MJ, Williams TM, Errtizoe D, et al. Broadband cortical desynchronization underlies the human psychedelic state. J Neurosci. 2013 Sep;33(38):15171-83.

4. Carhart-Harris RL, Erritzoe D, Williams T, Stone JM, Reed LJ, Colasanti A, et al. Neural correlates of the psychedelic state as determined by fMRI studies with psilocybin. Proc Natl Acad Sci USA. 2012 Feb;109(6):2138-43.

5. Palhano-Fontes F, Andrade KC, Tofoli LF, Santos AC, Crippa JA, Hallak JE, et al. The psychedelic state induced by ayahuasca modulates the activity and connectivity of the default mode network. PLoS One. 2015 Feb;10(2):e0118143.

6. Parnia S, Fenwick P. Near death experiences in cardiac arrest: visions of a dying brain or visions of a new science of consciousness. Resuscitation. 2002 Jan;52(1):5-11.

7. University of Virginia Division of Perception Studies. Children who remember previous lives. Available from: https://med.virginia.edu/perceptual-studies/ publications/academic-publications/children-who-remember-previous-lives-academic-publications/

8. Koch C. What is consciousness? Nature (2018). Available from: https://www.nature.com/articles/ d41586-018-05097-x

9. Miller G. What is the biological basis of consciousness? Science. 2005 Jul;309(5731):79. Available from: https:// science.sciencemag.org/content/309/5731/79.full

10. Jepsen K. Everything is made of fields. Symmetry. 2013. Available from: https://www.symmetrymagazine.org/ article/july-2013/real-talk-everything-is-made-of-fields

11. Francis M. What is a particle? Symmetry. 2016. Available from: https://www.symmetrymagazine.org/article/ what-is-a-particle

12. Sciamanda R. There are no particles, and there are no fields. Am J Phys. 2013;81(9):645-645. 
13. Kastrup B. Physics is pointing inexorably to mind. Scientific American. 2019. Available from: https:// blogs.scientificamerican.com/observations/ physics-is-pointing-inexorably-to-mind/

14. Henry RC. The mental Universe. Nature. 2005 Jul;436(7047):29. Available from: https://www.nature. com/articles/436029a

15. Kumar A. The three minds: A framework beyond biopsychosocial medicine. Essentia Foundation. 2021. Available from: https://www.essentiafoundation.org/ reading/the-three-minds-a-framework-beyond-biopsychosocial-medicine/

16. Kafatos M, Kak S. Veiled nonlocality and cosmic censorship. arXiv: Quantum Physics. 2014. Available from: https://arxiv.org/abs/1401.2180 